\title{
Hydrothermal synthesis of zinc oxide nanoparticles using rice as soft biotemplate
}

\author{
Donya Ramimoghadam ${ }^{1}$, Mohd Zobir Bin Hussein ${ }^{2^{*}}$ and Yun Hin Taufiq-Yap ${ }^{2}$
}

\begin{abstract}
Background: Rice as a renewable, abundant bio-resource with unique characteristics can be used as a bio-template to synthesize various functional nanomaterials. Therefore, the effect of uncooked rice flour as bio-template on physico-chemical properties, especially the morphology of zinc oxide nanostructures was investigated in this study. The $\mathrm{ZnO}$ particles were synthesized through hydrothermal-biotemplate method using zinc acetate-sodium hydroxide and uncooked rice flour at various ratios as precursors at $120^{\circ} \mathrm{C}$ for 18 hours.

Results: The results indicate that rice as a bio-template can be used to modify the shape and size of zinc oxide particles. Different morphologies, namely flake-, flower-, rose-, star- and rod-like structures were obtained with particle size at micro- and nanometer range. Pore size and texture of the resulting zinc oxide particles were found to be template-dependent and the resulting specific surface area enhanced compared to the zinc oxide synthesized without rice under the same conditions. However, optical property particularly the band gap energy is generally quite similar.

Conclusion: Pure zinc oxide crystals were successfully synthesized using rice flour as biotemplate at various ratios of zinc salt to rice. The size- and shape-controlled capability of rice to assemble the $\mathrm{ZnO}$ particles can be employed for further useful practical applications.
\end{abstract}

Keywords: Zinc oxide nanoparticles, Rice, Biotemplate, Soft templating, Starch, Hydrothermal method

\section{Background}

Remarkable improvements have been made using bioinspired approach for materials synthesis due to possible control of physico-chemical properties. A technique that employs natural materials as biotemplates to synthesize micro- and nano-scaled materials with morphologies and structures resemble to those of the biotemplate is called as biomorphic mineralization [1]. These kinds of works keep on growing and contributing to a new interdisciplinary areas, especially with the synthesis, self-assembly and processing of the organized inorganic materials [2].

Biotemplating approach is an impressive strategy to achieve the morphology-controllable materials with structural specialty, complexity and relevant fascinating functions. The advantages of applying biotemplates are that they are relatively cheap, economical, environmentally benign and renewable [3]. A series of natural biotemplates that were utilized in the fabrication of functional materials

\footnotetext{
* Correspondence: mzobir@putra.upm.edu.my

${ }^{2}$ Research center for Catalysis Science and Technology PutraCAT, Faculty of Science, Universiti Putra Malaysia, 43400 UPM, Serdang, Selangor, Malaysia Full list of author information is available at the end of the article
}

includes DNA [4], proteins [5], viruses [6], bacteria [7], diatoms [8], pollen grains [9], shell membrane, wood [10] and cellulose fibers [11].

Application of metal oxides materials have extensively arisen throughout human civilization and the uses of nano-sized particles are even more significant. Among them, $\mathrm{ZnO}$ nanoparticles are always in the center of attention due to their fascinating properties and extensive application. Bio-inspired synthesis of $\mathrm{ZnO}$ nanoparticles has been achieved using environmentally and ecofriendly accepted systems. Several studies have been investigated the use of natural materials for $\mathrm{ZnO}$ nanoparticles synthesis such as DNA [12], silk [13], albumen [14], orange juice [15], pea starch [16], peptide structures [17] and etc. The use of nanoparticles derived from noble metals has spread in many areas involving medical fields, electronics, antibacterial textiles, etc. As a matter of fact, orientation, size and physical properties of nanoparticles affect the performance and reproducibility of a potential device. Thus the synthesis and assembly of shape- and size-controlled nanocrystals are essential components for any practical applications.
() Chemistry Central

(c) 2013 Ramimoghadam et al.; licensee Chemistry Central Ltd. This is an Open Access article distributed under the terms of the Creative Commons Attribution License (http://creativecommons.org/licenses/by/2.0), which permits unrestricted use, distribution, and reproduction in any medium, provided the original work is properly cited. 
Agricultural materials particularly those containing cellulose indicate potential metal bio-sorption capacity. The basic components of the agricultural materials include hemi-cellulose, lignin, extractives, lipids, proteins, etc. [2]. Rice is an agricultural bio-resource which can be used as non-metalic bio-precursor to synthesize functional materials [1]. The main component of rice is starch which is one of the most fascinating bioresource that can be used for nanotechnology application. The carbohydrate polymeric chains build up from glucose units and parted in linear amylase and branched amylopectin. These peculiarities are representing the key structural elements for the synthesis of new functional nanomaterials [18]. Starchbased oxides with biocompatible and non-toxic features, grant a new class of functional nanomaterials with potential application in various industries. Therefore using rice as a soft biotemplate appears to be a promising way to synthesize zinc oxide nanoparticles. In our study, rice was chosen to be used as a soft template material due to its high porous structure, special components and relatively low cost. Lots of studies have been conducted to investigate the use of rice husk $[1,19]$ and starches $[20,21]$ for the synthesis of various functional materials. However, to the best of our knowledge, no such study on the synthesis of $\mathrm{ZnO}$ nanoparticles using rice as biotemplate is found in the open literature. Therefore, this study will contribute some input to the body of knowledge and worth to be carried out. The main objective of this research is to determine the effects of uncooked rice as a biotemplate on $\mathrm{ZnO}$ physico-chemical properties, particularly its morphology and surface properties. Due to easy controlling of the size, shape and water solubility of $\mathrm{ZnO}$, then the biocompatibility and functionality of $\mathrm{ZnO}$ nanomaterials could be further improved by surface modification [13].

\section{Results and discussion XRD analysis}

Figure 1 shows the XRD patterns of the samples synthesized using different concentrations of uncooked rice powder by hydrothermal method. All the diffraction peaks can be indexed as hexagonal wurtzite-structure (JCPDS card No. 36-1451). The sharp and narrow peaks also illustrate that $\mathrm{ZnO}$ particles enjoy high crystallinity and purity. As clearly seen from Figure 1, the intensity of the XRD peaks for assynthesized $\mathrm{ZnO}$ samples was decreased by increasing the concentration of UR, this is due to presence of biotemplate. Even though very little amount of biotemplate present in the sample, no characteristic peaks of rice components can be observed in the XRD pattern. Therefore, employing UR as biotemplate could result in the synthesis of relatively pure $\mathrm{ZnO}$ particles.

\section{Morphology and size}

Figure 2 shows field emission scanning electron microscopy (FESEM) images of the samples synthesized at different concentrations of uncooked rice (UR). To investigate the effects of raw rice on the resulting $\mathrm{ZnO}$ morphology, FESEM images of $\mathrm{ZnO}$ synthesized without UR are also

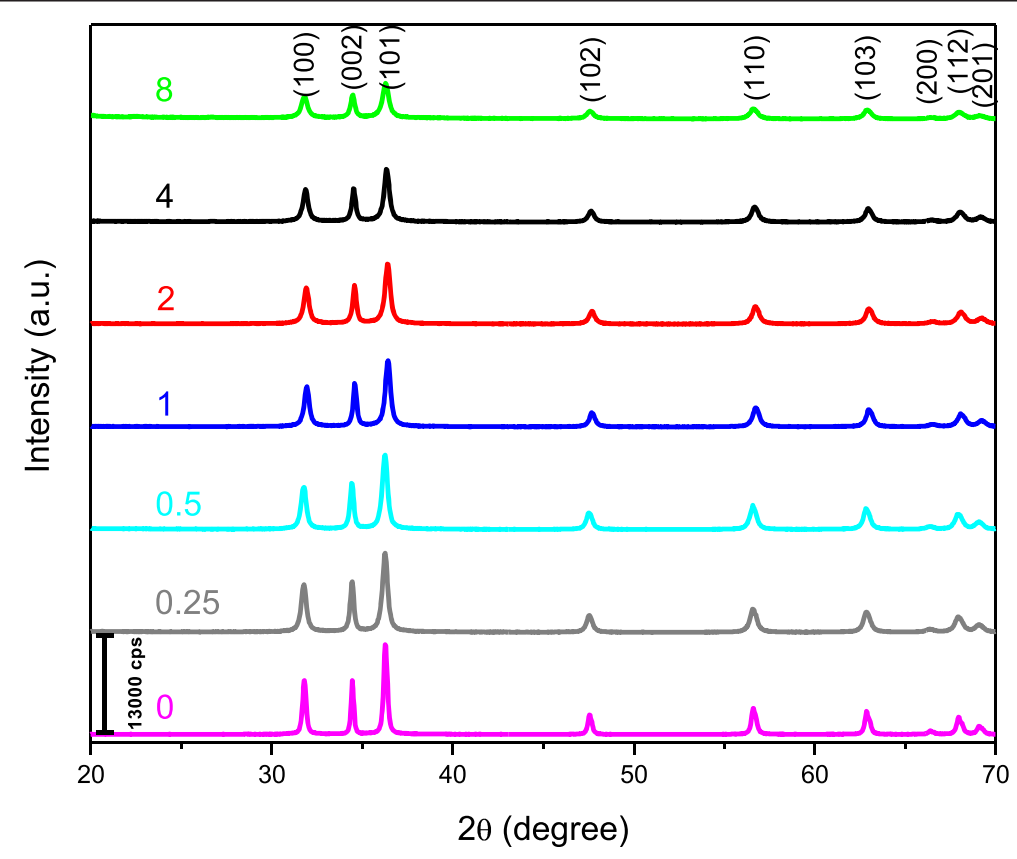

Figure 1 Powder X-ray diffraction (PXRD) patterns of as-synthesized ZnO prepared at different concentrations of uncooked rice powder; $0,0.25,0.5,1,2,4,8 \mathrm{~g}$ (w/w\%). 


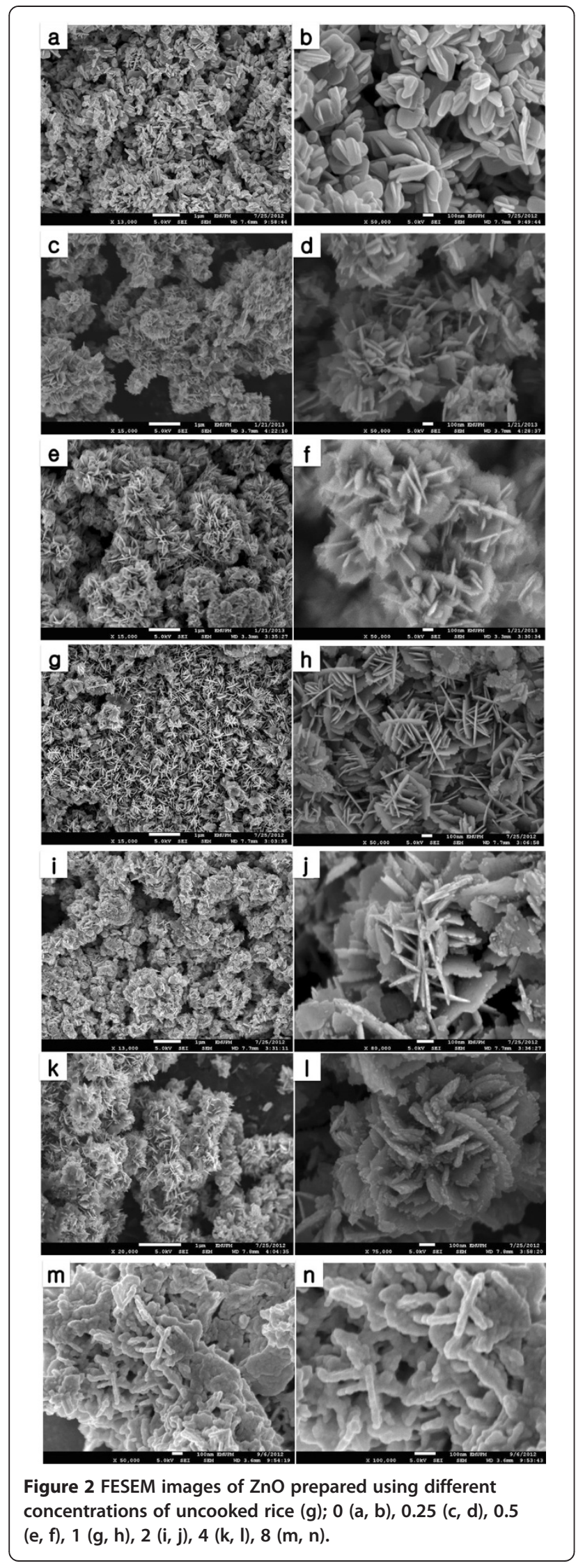

shown in Figure 2a and b. As seen in Figure 2c and d, the $\mathrm{ZnO}$ structures show mostly flake-like structures assembling together. They are much more ordered in contrast to the one synthesized without UR (as a control) (Figure 2a and b). The diameter of $\mathrm{ZnO}$ flakes dramatically decreased after adding $0.25 \mathrm{~g}$ UR. This may occur due to the inhibition of lateral growth of $\mathrm{ZnO}$ crystals. Indeed, the accessibility of the zinc ions to the $\mathrm{ZnO}$ crystal seeds was controlled by biotemplate. However, size of particles seems to be increased when the synthesis was done using $0.25 \mathrm{~g}$ UR. Different morphologies of as-synthesized $\mathrm{ZnO}$ was observed with increasing the amount of uncooked rice to $0.5 \mathrm{~g}$. Particles with very small flower-like shape can be observed in Figure 2e and f. Lower magnification of FESEM image indicates that the mentioned structure shows denticulated petals aggregated and form larger flowers of particles. It is notable that the size of the $\mathrm{ZnO}$ particles has been obviously decreased for sample prepared using $0.5 \mathrm{~g}$ UR. In addition, the tooth-like flakes are more dominant for the $\mathrm{ZnO}$ sample prepared using $0.5 \mathrm{~g}$ UR compared to the one synthesized using $0.25 \mathrm{~g}$ UR.

Figure $2 \mathrm{~g}$ and $\mathrm{h}$ indicate the FESEM images of $\mathrm{ZnO}$ sample synthesized using $1 \mathrm{~g}$ UR. Very unique star-like structure can be clearly observed at low to high magnification. The star-like structure contains small flakes with denticulated edges which attach to other similar flakes in the center. A closer look shows that the lateral flake act as a substrate for other flakes to grow on the surface and form star-like structure. Similar structure was also reported in literature, confirming that the branched pattern for soft templates, starch, revealing that the semicrystalline granules of starch are made from concentric rings in which the amylose and amylopectin, basic components are aligned perpendiculary to the growth rings and to the granule surface [22]. Figure $2 \mathrm{~g}$ and $\mathrm{h}$ shows that the size of the star-like $\mathrm{ZnO}$ particles decreased in comparison with the previous lower amount of uncooked rice.

In the case of $\mathrm{ZnO}$ crystals synthesized at $2 \mathrm{~g}$ UR, increasing the amount of biotemplate resulted in different morphologies of $\mathrm{ZnO}$ particles produced. It formed lots of agglomerated toothed-edge flakes which become a secondary unit for bigger particles. The star-like shape of the particles can be perceived in some areas but aggregation seems to be dominant and prevented clearer observation of the particles as they really are.

Figure $2 \mathrm{k}$ and $\mathrm{l}$ show FESEM images for assynthesized $\mathrm{ZnO}$ particles synthesized using $4 \mathrm{~g}$ UR. The $\mathrm{ZnO}$ morphology changed to flower-like structures, mostly rose-like shapes. Detailed view on flower-like particles reveals that their flakes have largest diameter compared to other samples. In the case of $\mathrm{ZnO}$ synthesized using $8 \mathrm{~g}$ UR, a new morphology, different from other and 
control samples was observed. The $\mathrm{ZnO}$ crystals show mostly rods with around $100 \mathrm{~nm}$ size. Moreover, agglomerated without any specific shape particles coexisted with nanorods in the structure of $\mathrm{ZnO}$ synthesized using $8 \mathrm{~g}$ UR.

The rice main component is carbohydrates which is polysaccharides. In synthesis of nanosized oxide-based materials, carbohydrate can play multiple roles, namely coating/capping, functionalizing, stabilizing, poring and/ or coordinating agent. In one hand, polymeric structure of starch with helical-shaped carbonaceous matrix which carrying multiple polyol groups create a protective and functionalized surrounding shield for metal ions which plays a structure-directing role. The hydroxyl groups of amylopectin could be involved both in intra- and/or intermolecular supramolecular association. They are able to coordinate transition metal ions, maintaining the nanoparticles highly aggregated [18,23]. Rice granules swell in aqueous solution and their semi-crystalline structure is lost as the smaller amylose molecules start leaching out of the granule. The small amylose molecules can form complexes with $\mathrm{Zn}^{2+}$ because of their high number of coordinating functional groups. It is likely that the majority of the zinc ions are closely associated with the starch molecules, so nucleation and initial crystal growth might preferentially occur within regions of both high starch concentration and high $\mathrm{Zn}^{2+}$ concentration [21]. The Van der Waals interactions between the surface molecules of the nanocrystallites form the driving force for self-assembly, and then $\mathrm{ZnO}$ nanocrystals can be assembled to form larger $\mathrm{ZnO}$ crystals [24], which explain the basis of the growth mechanism of zinc oxide crystals when raw rice was used as template.

Figure 3 shows the particle size distribution of the $\mathrm{ZnO}$ samples synthesized using 0.25, 0.5, 1, 2, 4, $8 \mathrm{~g}$ UR. Particle size distribution of $\mathrm{ZnO}$ synthesized without rice is also given for comparison. As shown in Figure 3, the range of particle size for $\mathrm{ZnO}$ synthesized without UR lies between $200-800 \mathrm{~nm}$. When $0.25 \mathrm{~g}$ UR was used in the synthesis, size of particles increased dramatically to 800-2000 nm. It is notable that size of $\mathrm{ZnO}$ synthesized using $0.5 \mathrm{~g}$ UR, considerably decreased to $200-1000 \mathrm{~nm}$ range. The decreasing trend continues for sample synthesized at $1 \mathrm{~g}$ UR and with a size range of $250-700 \mathrm{~nm}$. Although this distribution is quite similar to that of $\mathrm{ZnO}$ synthesized without biotemplate, it is slightly narrower. On the basis of particle size distribution for the samples synthesized using 2 and $4 \mathrm{~g}$ UR, it can be clearly observed that the size of particles decreased to 200$700 \mathrm{~nm}$ and $150-700 \mathrm{~nm}$, respectively. In the case of $\mathrm{ZnO}$ sample synthesized at $8 \mathrm{~g}$ UR, the size of particles is at the nano size regime, between $40-100 \mathrm{~nm}$. As mentioned in growth mechanism, adding biotemplate

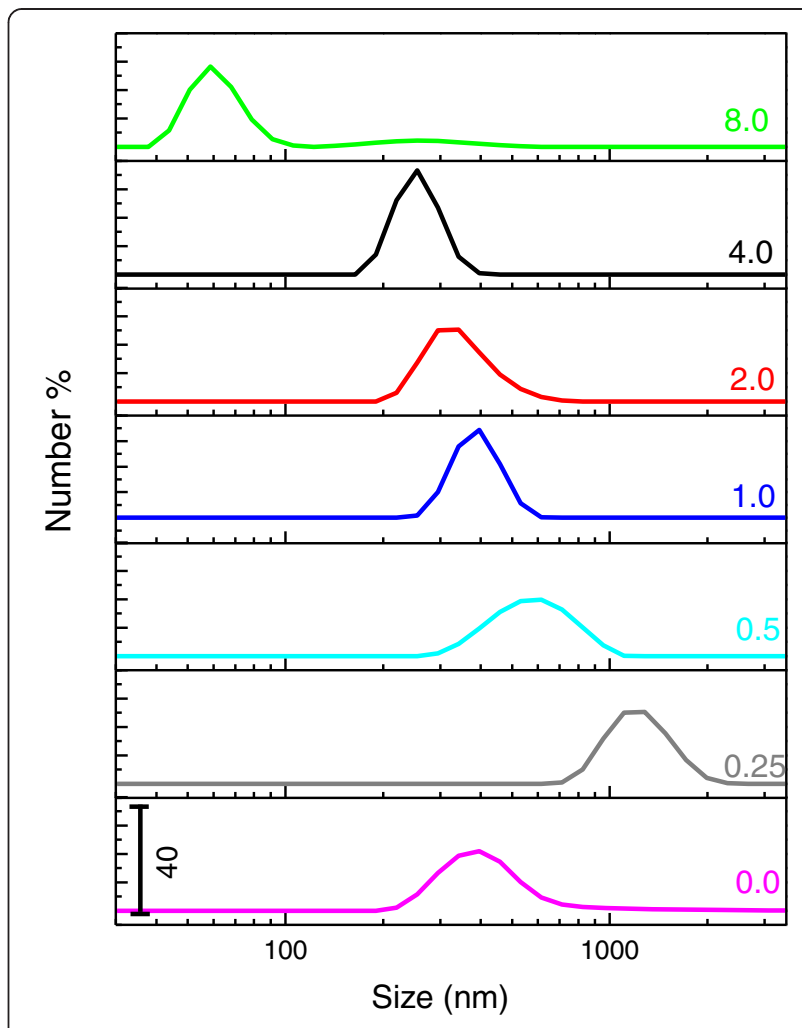

Figure 3 Particle size distribution of $\mathrm{ZnO}$ samples synthesized using various concentrations of UR (g); 0, 0.25, 0.5, 1, 2, 4, 8 (w/w\%).

presumably acted as flocculants and forces aggregation. Therefore, the surface-active sites of the template might influence the size and state of aggregation during the particle growth process [25] and finally on the resulting $\mathrm{ZnO}$ particles size distribution.

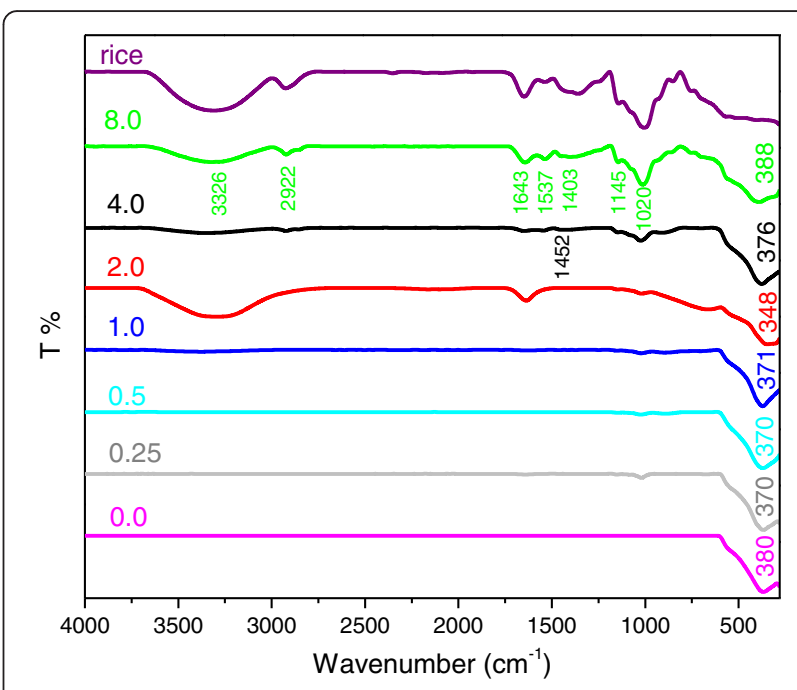

Figure $4 \mathrm{FTIR}$ spectra of $\mathrm{ZnO}$ samples synthesized using various concentrations of UR in the range of $4000-280 \mathrm{~cm}^{-1}$ without calcination. 


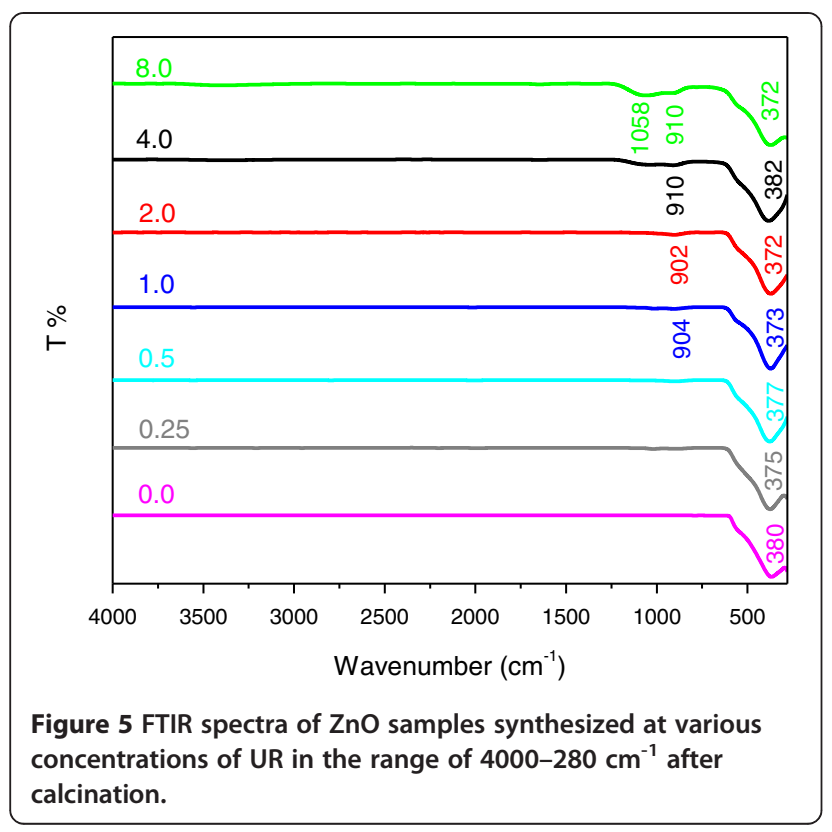

\section{FTIR spectroscopy}

FTIR spectroscopy was used to investigate the effect of biotemplate (rice) on the resulting chemical properties of the $\mathrm{ZnO}$ nanostructures prepared by hydrothermal method. FTIR spectra were obtained at room temperature in the range of $4000-280 \mathrm{~cm}^{-1}$. Figure 4 shows the FTIR spectra for the as-prepared $\mathrm{ZnO}$ nanostructures synthesized using different concentrations of UR. Generally, rice contains mainly starch (carbohydrates) and water with minor components such as proteins, vitamins, lipids, etc. These compositions mostly consist of alkene, esters, aromatics and alcohols with different combination of functional groups. As shown in Figure 4, the FTIR spectra of the products involve characteristic peaks of rice, such as a broad band at 3300$3400 \mathrm{~cm}^{-1}$ is attributed to $-\mathrm{OH}$ stretching vibrations, possibly including $\mathrm{H}_{2} \mathrm{O}$, alcoholic $\mathrm{OH}$, phenolic $\mathrm{OH}$ and/or carboxylic $\mathrm{OH}$ [26]. A band at $2922 \mathrm{~cm}^{-1}$ is assigned to stretching vibrations of aliphatic $\mathrm{CH}$. Moreover, absorption band at $1640 \mathrm{~cm}^{-1}$ represents the hydroxyl group of chemisorbed and/or physisorbed $\mathrm{H}_{2} \mathrm{O}$

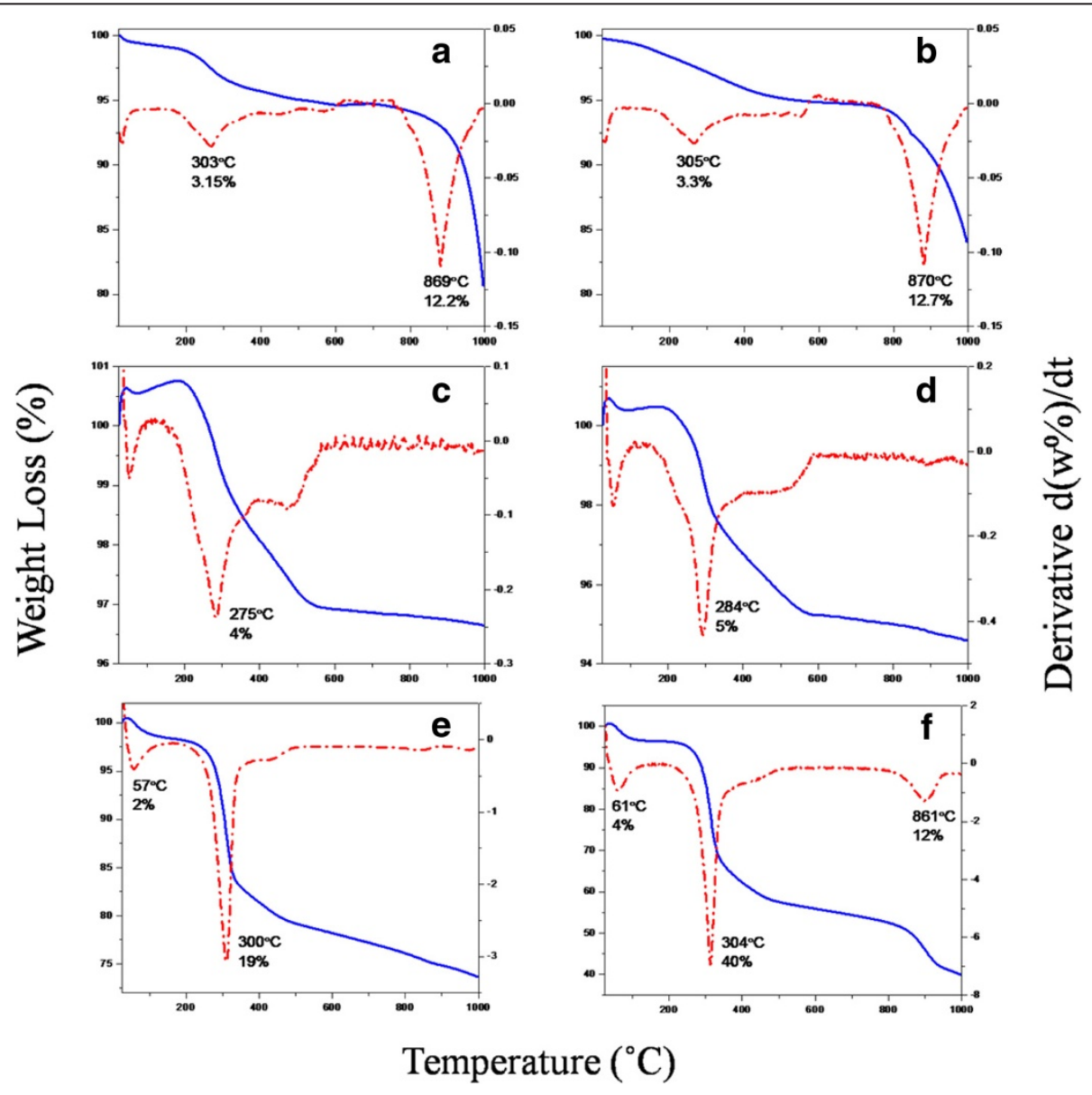

Figure 6 Thermogravimetric and differential thermogravimetric thermograms (TGA-DTG) of as-synthesized ZnO samples synthesized using various concentrations of UR (a) 0.25 , (b) 0.5 , (c) 1, (d) 2, (e) 4 and (f) $8 \mathrm{~g}$. 


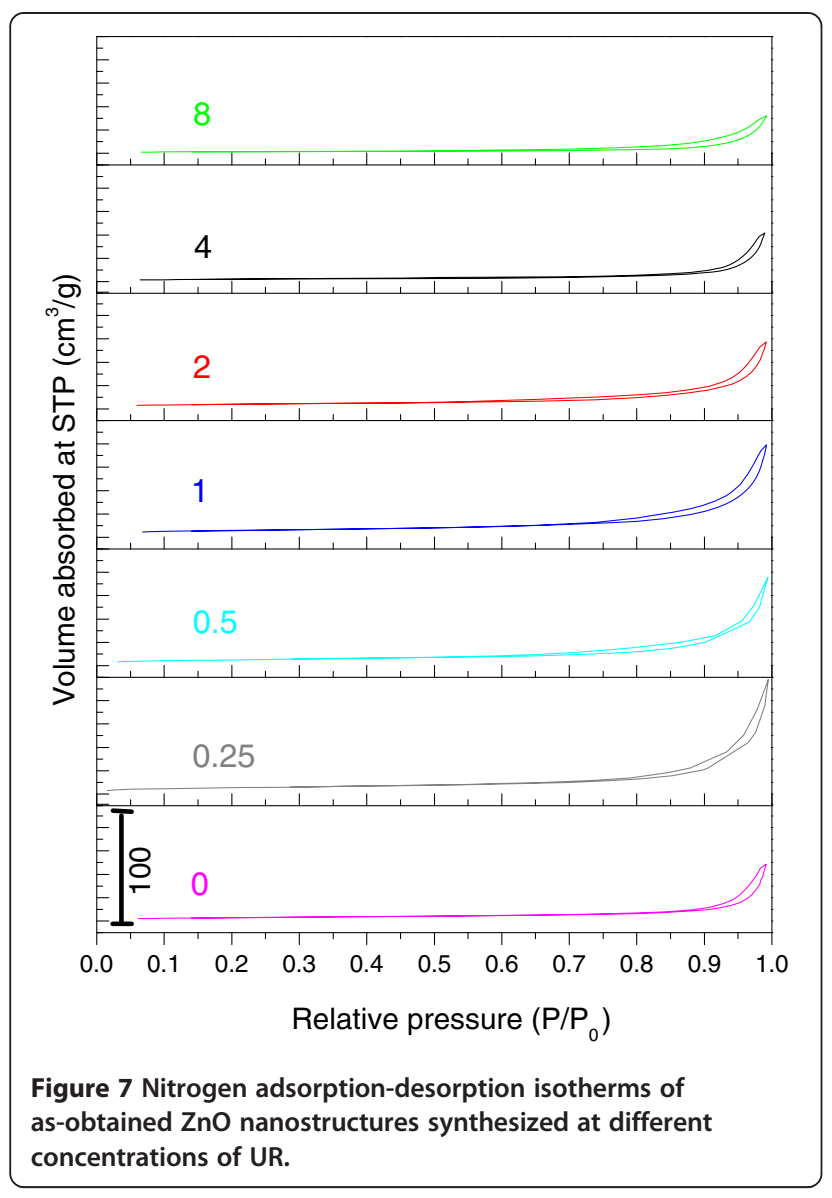

molecules on the particle surface [27]. Bands at around 1450 and $1400 \mathrm{~cm}^{-1}$ are attributed to the $\mathrm{C}-\mathrm{H}$ bending and angular deformation of $\mathrm{C}-\mathrm{H}$ bond in starch molecule, respectively [28]. Absorption band at $1145 \mathrm{~cm}^{-1}$ ascribed to $\mathrm{C}-\mathrm{O}$ bond stretching of the $\mathrm{C}-\mathrm{O}-\mathrm{H}$ group and two bands at 1079 and $1020 \mathrm{~cm}^{-1}$ are assigned to $\mathrm{C}-\mathrm{O}$ bond stretching of the $\mathrm{C}-\mathrm{O}-\mathrm{C}$ group in the anhydroglucose ring of starch [29]. The absorptions at $1300-900 \mathrm{~cm}^{-1}$ might be allocated to the silicon compounds and silicates, which is ascribed to the $\mathrm{Si}-\mathrm{C}$ or $\mathrm{Si}-\mathrm{O}$ fundamental stretching vibration [30]. The silicon compound may coexist with other compositions in the rice due to the presence of rice husk.

Figure 5 shows the FTIR spectra for the $\mathrm{ZnO}$ nanostructures synthesized using various concentrations of UR after calcinations at $500^{\circ} \mathrm{C}$ for 5 hours. All the absorption bands due to rice disappeared from the FTIR spectra. Two new bands at about $900 \mathrm{~cm}^{-1}$ and $1058 \mathrm{~cm}^{-1}$ appear after calcinations treatment which can be assigned to the skeleton vibrational mode of glycosidic linkage (C-O-C) and $\mathrm{C}-\mathrm{H}$ bending of starch molecules [31]. The characteristic bands of $\mathrm{ZnO}$ before calcination can be observed at about $350-390 \mathrm{~cm}^{-1}$ which after calcinations shifted to higher wavenumbers of $370-380 \mathrm{~cm}^{-1}$.

\section{Thermal analysis}

Figure 6 shows thermal analysis of the as-synthesized $\mathrm{ZnO}$ synthesized using various concentrations of UR $(0.25,0.5,1,2,4$ and $8 \mathrm{~g})$. Generally, three main decomposition steps can be observed; the first weight loss occurs at below $100^{\circ} \mathrm{C}$, assigned to dehydration of water. The percentages of water loss increased from low

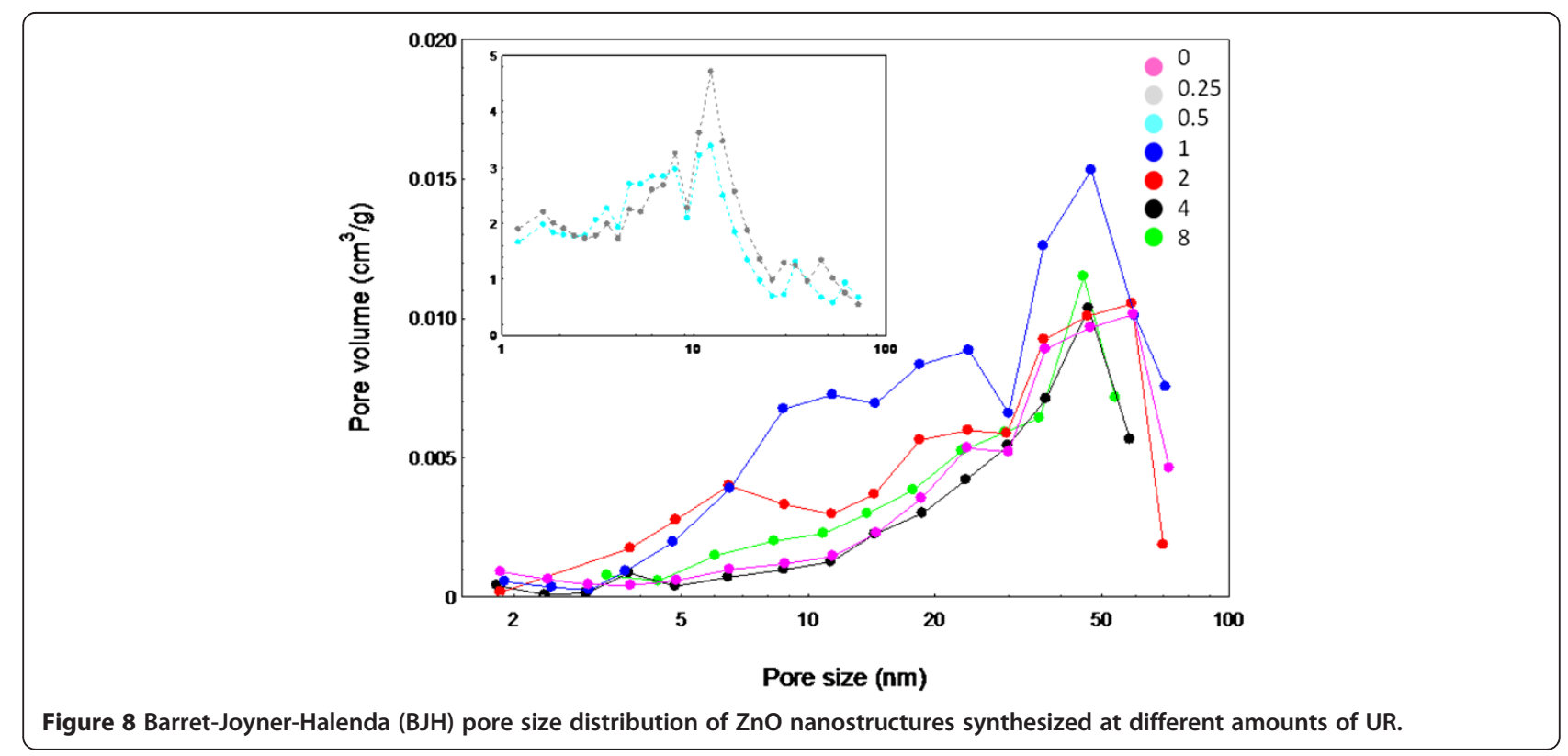


concentration of rice $(0.25 \mathrm{~g})$ with below $1 \%$ weight loss to the highest one $(8 \mathrm{~g})$ with $4 \%$ weight loss. The low values of water loss are not shown in the thermograms. The second weight loss at about $300^{\circ} \mathrm{C}$ is assigned to the decomposition of rice flour components, mainly carbohydrates [32]. It is noteworthy that similar to the first decomposition, the weight loss percentages for second step increased with the increasing of the rice concentration in the samples. In other words, weight losses of 3.15, 3.3, 4, 5,19 and $40 \%$ can be observed for samples with $0.25,0.5$, 1, 2, 4 and $8 \mathrm{~g}$ UR, respectively. Similar results were also reported by Zhang et al. [20] indicating that weight loss in the range of $190-490^{\circ} \mathrm{C}$ is attributed to the thermal decomposition and oxidation of soluble starch. The third decomposition at above $850^{\circ} \mathrm{C}$ is due to the degradation of the rice components residual with zinc acetate [33].

\section{Surface properties}

The nitrogen adsorption-desorption isotherms for $\mathrm{ZnO}$ nanoparticles prepared at different concentrations of UR are shown in Figure 7. All the isotherms can be ascribed as Type IV according to IUPAC classification, indicating mesoporesdominated property. Moreover, their hysteresis loop is interpreted as Type $\mathrm{H} 3$ representing aggregates of plate-like particles giving rise to slit-shaped pores. On the basis of the results from Figure 7, adsorption on these samples proceeds via multilayer formation in such a manner that the amount adsorbed increases gradually as the relative pressure increases. However, at higher pressures the amount adsorbed rises very steeply due to the capillary condensation in pores.

Generally, the volume absorbed for samples synthesized using $0.25,0.5,1$ and $2 \mathrm{~g}$ UR is higher than that of $\mathrm{ZnO}$ synthesized without UR. It is notable that maximum volume absorbed is observed for the sample synthesized using $0.25 \mathrm{~g}$ UR with value of $98 \mathrm{~cm}^{3} / \mathrm{g}$. The decreasing trend for volume absorbed value for rest of the samples can be clearly observed from Figure 7. These dramatic changes in the adsorption behavior are often caused by surface modifications, which manifested itself in a significant decrease in the amount adsorbed [34]. The desorption branches of the isotherms are also in good agreement with this result. The desorption branches of samples are quite different due to the modification has occurred in their pore's texture.

In addition, H3 hysteresis usually indicates loosely assembled aggregated plate-like particles forming slit-like pores. However, changes can be observed from hysteresis loops. In the case of the sample synthesized using $8 \mathrm{~g}$ UR, an almost horizontal desorption branch with least volume adsorbed can be observed. Therefore this shows that modification in the pore texture of $\mathrm{ZnO}$ samples synthesized at different concentrations of UR has been occurred.

Figure 8 shows the Barret-Joyner-Halenda (BJH) pore size distribution for the samples synthesized at different concentrations of UR. As clearly seen from the plots,
Table 1 BET surface area, BJH pore size diameter and pore volume of $\mathrm{ZnO}$ nano- microstructures synthesized at different concentrations of UR

\begin{tabular}{cccc}
\hline UR (g) & $\begin{array}{c}\text { BET surface } \\
\text { area }\left(\mathbf{m}^{2} / \mathbf{g}\right)\end{array}$ & $\begin{array}{c}\text { BJH pore } \\
\text { diameter }(\mathbf{n m})\end{array}$ & $\begin{array}{c}\text { BJH pore } \\
\text { volume }\left(\mathbf{c m}^{\mathbf{3}} / \mathbf{g}\right)\end{array}$ \\
\hline 0.0 & 5 & 23 & 0.07 \\
0.25 & 17 & 28 & 0.12 \\
0.5 & 16 & 26 & 0.10 \\
1.0 & 22 & 20 & 0.12 \\
2.0 & 15 & 20 & 0.08 \\
4.0 & 8 & 25 & 0.06 \\
8.0 & 5 & 20 & 0.04 \\
\hline
\end{tabular}

pores are located mainly between $2-50 \mathrm{~nm}$, indicating that the material is dominated by mesoporous structure, which is in good agreement with the results of Type IV adsorption-desorption isotherms. However, due to the observation of hysteresis loops which shifted to a high relative pressure of $\mathrm{P} / \mathrm{P}_{0} \approx 1$, the presence of large pores $(>50 \mathrm{~nm})$ is possible [35]. For better comparison, pore size distribution of as-synthesized $\mathrm{ZnO}$ synthesized without UR is also given, showing rather similar property to that of $\mathrm{ZnO}$ synthesized using $2 \mathrm{~g}$ UR with size distribution of around $60 \mathrm{~nm}$ with more than one distribution. The pore sizes of $\mathrm{ZnO}$ samples prepared using 0.25, 0.5, 1, 4 and $8 \mathrm{~g}$ UR are distributed at around 12, 12, 48, 47 and $46 \mathrm{~nm}$, respectively. Due to known non-porous structure of $\mathrm{ZnO}$, the pores observed were due to inter- and intraparticles agglomeration of secondary and tertiary types.

The BET surface area and the average pore diameter and pore volume of $\mathrm{ZnO}$ nanostructures synthesized at various concentrations of UR are listed in Table 1. The average pore diameter of the samples lies between $20-28 \mathrm{~nm}$. The

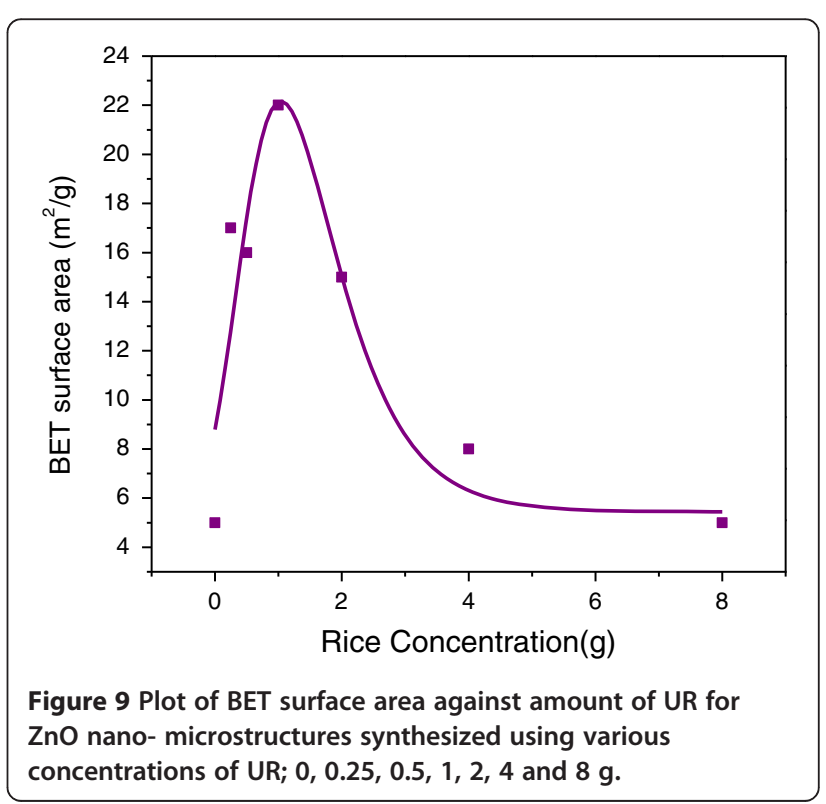


maximum pore volumes for samples synthesized using 0.25 and $1 \mathrm{~g}$ UR are the same, $0.12 \mathrm{~cm}^{3} / \mathrm{g}$. BET surface area values for $\mathrm{ZnO}$ nanostructures synthesized at different concentrations of UR is shown in Figure 9. BET surface area value increase with the increasing of the uncooked rice amount up to $22 \mathrm{~m}^{2} / \mathrm{g}$ (at $1 \mathrm{~g}$ UR) and then decreased thereafter. The decrease in surface area is presumably due to the formation of bigger agglomeration at high UR ratio more than $1 \mathrm{~g}$. The optimum BET surface area was observed for the $\mathrm{ZnO}$ sample synthesized using $1 \mathrm{~g} \mathrm{UR}$.

\section{Optical properties}

The UV-visible absorption spectra of as-synthesized $\mathrm{ZnO}$ nanostructures are shown in Figure 10a. All the curves show absorption below $400 \mathrm{~nm}$, corresponding to the intrinsic band gap of $\mathrm{ZnO}$ which is related to electron transitions from the valence band to conduction band. In addition, the samples synthesized at different concentrations of UR indicate higher UV-vis absorption compared to the one synthesized without UR. The direct-band gap energies as shown in Figure 10b were
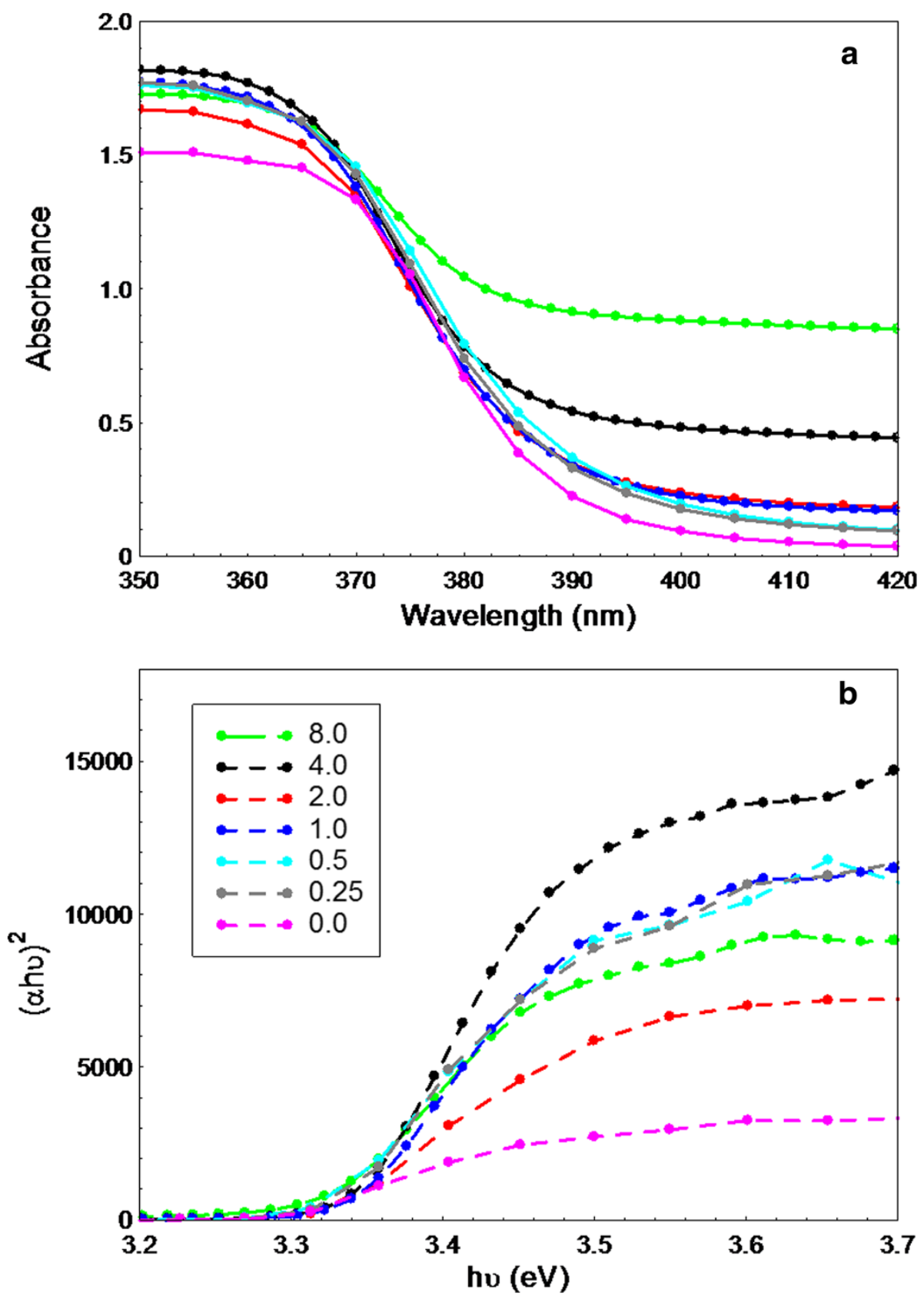

Figure 10 UV-visible absorption spectra (a) and Band gap energy (b) of as-synthesized ZnO nanostructures synthesized at different concentrations of UR. 
estimated from the plots of the transformed KubelkaMunk function $(\alpha h v)^{2}$ versus the photon energy (hv). As seen in Figure 10b, linear region of the plot can be extrapolated to intersect the $\mathrm{x}$-axis, and this value is identified as $E_{g}$, the band gap energy. The $E_{g}$ of as-synthesized $\mathrm{ZnO}$ prepared using $0,0.25,0.5,1,2,4$ and $8 \mathrm{~g}$ UR were found to be very similar, 3.29, 3.32, 3.32, 3.34, 3.32, 3.34 and $3.32 \mathrm{eV}$, respectively, in agreement with similar crystal structure as indicated by XRD results.

\section{Experimental procedure}

All chemicals used in this work were of analytical reagent grade and used as received without any further purification. All aqueous solutions were prepared using deionized water. The raw rice was purchased from a local market and then ground into powder form in a milling machine, Fritsch Pulverisette 6 type planetary monomill, Germany.

In a typical procedure, $1 \mathrm{~g}$ of zinc acetate $\left(\mathrm{Zn}(\mathrm{Ac})_{2} \cdot 2 \mathrm{H}_{2} \mathrm{O}\right)$ and $0.8 \mathrm{~g}$ sodium hydroxide $(\mathrm{NaOH})$ were dissolved in $25 \mathrm{~mL}$ distilled water under constant stirring $\left(\mathrm{Zn}^{2+}\right.$ : $\left.\mathrm{OH}^{-}=1: 4\right)$. The measured $\mathrm{pH}$ was 13 . After 1 hour stirring, different concentrations of rice powder $0,0.25,0.5,1$, 2, 4 and $8 \mathrm{~g}$ were introduced into the solution (the ratio of zinc acetate to rice powder was chosen at i.e. 1:0, 1:0.25, 1:0.5, 1:1, 1:2, 1:4 and 1:8 w/w\%) and stirring was continued until the rice powder was completely dissolved. The solutions with lower concentrations of rice powder were easily dissolved and the color of solution remained white. In higher concentrations of rice powder, yellowish solutions after longer time of stirring were observed. Attempt has been made to use higher concentrations of rice, $16 \mathrm{~g}$, but the resulting solution was very difficult of dissolve and therefore the experiment was discarded. Finally the mentioned solution was transferred into a Teflon-lined stainless steel autoclave, $50 \mathrm{~mL}$ and hydrothermal growth was carried out at $120^{\circ} \mathrm{C}$ for $18 \mathrm{~h}$. After treatment, the autoclaves were allowed to cool down and the precipitates were collected, centrifuged at $40,000 \times \mathrm{g}$ for $10 \mathrm{~min}$ and supernatant was discarded. The obtained particles were washed three times with ethanol and distilled water in order to remove impurities and dried at $60^{\circ} \mathrm{C}$ for $24 \mathrm{~h}$.

\section{Characterization}

Powder X-ray diffraction (PXRD) analysis was performed on a Shimadzu diffractometer, XRD-6000 (Tokyo, Japan) equipped with $\mathrm{CuK}_{\alpha}$ radiation. The morphology of the micro- and nanostructures were characterized by field emission scanning electron microscopy (FESEM) a JOEL JSM-6400 (Tokyo, Japan). Surface characterization of the material was carried out using nitrogen gas adsorptiondesorption technique at $77 \mathrm{~K}$ using a Micromeritics ASAP 2000 (Norcross, GA, USA). Thermogravimetric and differential thermogravimetric analysis (TGA-DTG) were carried out using a Mettler Toledo instrument (Greifensee, Switzerland) using a heating rate of $10^{\circ} \mathrm{C} / \mathrm{min}$, in the range of $25-1000^{\circ} \mathrm{C}$ under nitrogen atmosphere. Fourier transform infrared spectra were recorded over the $280-4000 \mathrm{~cm}^{-1}$ range using a Perkin-Elmer 100 spectrophotometer (Waltham, MA, USA) under standard conditions. The UV-VIS-NIR spectrophotometer UV-3600 SHIMADZU was used to determine the optical properties.

\section{Conclusion}

Uncooked rice, a bioresource can be used as biotemplate for morphology directing agent for the synthesis of $\mathrm{ZnO}$ micro- and nanostructures by hydrothermal method. The effects of uncooked rice on $\mathrm{ZnO}$ properties were investigated. Various ratios of rice were used and was found to change the morphology and size of the resulting $\mathrm{ZnO}$ crystals with different structures; flower-, flake-, rose-, star- and rod-like. The growth mechanism of $\mathrm{ZnO}$ crystals is possibly directed by conjugated and/or competing chemical/supramolecular interaction between zinc ions and the main component of the rice, carbohydrates. Surface modification of rice on the resulting $\mathrm{ZnO}$ was observed through pore texture and specific surface area.

\section{Abbreviations \\ BET: Brunauer-Emmett-Teller; BJH: Barret-Joyner-Halenda; DTG: Differential thermogravimetric analysis; $E_{g}$ : Band gap energy; eV: Electron volt; FESEM: Field emission scanning electron microscopy; FTIR: Fourier transform infrared; g: Gram; h: Hour; IUPAC: International union of pure and applied chemistry; JCPDS: Joint committee on powder diffraction standards; nm: Nanometer; No.: Number; TGA: Thermogravimetric analysis; UR: Uncooked rice; UV: Ultraviolet; XRD: X-ray diffraction; $\mathrm{Zn}^{2+}$ : Zinc cation; ZnO: Zinc oxide.}

\section{Competing interests}

There is no conflict of interest for all authors of this article.

\section{Authors' contributions}

DR is the first author of this article. MZBH is the second and correspond author. YHTY is the third author. All authors read and approved the final manuscript.

\section{Acknowledgements}

The authors are gratefully acknowledged the Ministry of Higher Education of Malaysia (MOHE) for financial support under grant No. FRGS/1/11/SG/UPM/ 01/2 (Vot No. 5524165).

\section{Author details}

${ }^{1}$ Material Synthesis and Characterization Laboratory (MSCL), Institute of Advanced Technology (ITMA), Universiti Putra Malaysia, 43400 UPM, Serdang, Selangor, Malaysia. ${ }^{2}$ Research center for Catalysis Science and Technology PutraCAT, Faculty of Science, Universiti Putra Malaysia, 43400 UPM, Serdang, Selangor, Malaysia.

\section{Received: 24 April 2013 Accepted: 25 July 2013}

Published: 6 August 2013

\section{References}

1. Yang D, Fan T, Zhou H, Ding J, Zhang D: Biogenic hierarchical TiO2/SiO2 derived from rice husk and enhanced photocatalytic properties for dye degradation. PLoS One 2011, 6(9):e24788.

2. Qinglei L, Fan T, Ding J, Guo Q: Bio-inspired functional materials templated from nature materials. kona powder and particle journal 2010, 28(28):116-130. 
3. Zhou H, Fan T, Zhang D: Biotemplated materials for sustainable energy and environment: current status and challenges. Chem Sus Chem 2011, 4(10):1344-87.

4. Seeman NC: DNA in a material world. Nature 2003, 421(6921):427-31.

5. McMillan RA, Paavola CD, Howard J, Chan SL, Zaluzec NJ, Trent JD: Ordered nanoparticle arrays formed on engineered chaperonin protein templates. Nat Mater 2002, 1(4):247-52.

6. Fowler $\mathrm{C}$, Shenton $\mathrm{W}$ : Tobacco mosaic virus liquid crystals as templates for the interior design of silica mesophases and nanoparticles. Adv Mater 2001, 37235(3):1266-1269.

7. Davis S, Patel $\mathrm{H}$ : Brittle bacteria: a biomimetic approach to the formation of fibrous composite materials. Chem Phys Lett 1998, 10:2516-2524.

8. Payne EK, Rosi NL, Xue C, Mirkin CA: Sacrificial biological templates for the formation of nanostructured metallic microshells. Angew Chem Int Ed Engl 2005, 44(32):5064-7.

9. Hall SR, Bolger H, Mann S: Morphosynthesis of complex inorganic forms using pollen grain templates Porous micron-sized particles of silica, calcium carbonate or by template-directed synthesis employing intact pollen. Chem Commun (Camb) 2003, 44:2784-2785.

10. Gao X, Matsui H: Peptide-based nanotubes and their applications in bionanotechnology. Adv Mater 2005, 17(17):2037-2050

11. He J, Kunitake T, Nakao A: Facile in situ synthesis of noble metal nanoparticles in porous cellulose fibers. Chem Mater 2003, 15(23):4401-4406.

12. Cai A-J, Wang Y-L, Xing S-T, Du L-Q, Ma Z-C: Tuned morphologies of DNAassisted $\mathrm{ZnO}$ struggling against pH. Ceram Int 2013, 39(1):605-609.

13. Han J, Su H, Xu J, Song W, Gu Y, Chen Y, Moon W-J, Zhang D: Silkmediated synthesis and modification of photoluminescent $\mathrm{ZnO}$ nanoparticles. Journal of Nanoparticle Research 2012, 14(2):726.

14. Nouroozi F, Farzaneh F: Synthesis and characterization of brush-like ZnO nanorods using albumen as biotemplate. J Braz Chem Soc 2011, 22(3):484-488.

15. Jha AK, Kumar V, Prasad K: Biosynthesis of metal and oxide nanoparticles using orange juice. Journal of Bionanoscience 2011, 5(2):162-166.

16. Yu J, Yang J, Liu B, Ma X: Preparation and characterization of glycerol plasticized-pea starch/ZnO-carboxymethylcellulose sodium nanocomposites. Bioresour Technol 2009, 100(11):2832-41.

17. Tomczak MM, Gupta MK, Drummy LF, Rozenzhak SM, Naik RR: Morphological control and assembly of zinc oxide using a biotemplate. Acta Biomater 2009, 5(3):876-82.

18. Visinescu D, Patrinoiu G, Tirsoaga A, Carp O: Polysaccharides route: a new green strategy for metal oxides synthesis. In Environmental Chemistry for a Sustainable World. vol. 1: Nanotechnology and Health Risk. Edited by Lichtfouse E, et al. Netherlands: Springer; 2012:119-169.

19. Rahman MM, Hasnida N, Wan Nik WB: Preparation of zeolite $Y$ using local Raw material rice husk as a silica source. J Sci Res 2009, 1(2):2-8.

20. Zhang G, Shen $X$, Yang $Y$ : Facile synthesis of monodisperse porous $\mathrm{ZnO}$ spheres by a soluble starch-assisted method and their photocatalytic activity. J Phys Chem C 2011, 115(15):7145-7152.

21. Taubert A, Wegner G: Formation of uniform and monodisperse zincite crystals in the presence of soluble starch. J Mater Chem 2002, 12(4):805-807.

22. Gidley M: Starch structure/function relationships: achievements and challenges. In Starch: advances in structure and function. Special publicationroyal society of chemistry. Great Britain: Food Chemistry Group; 2001:1-7.

23. Paraschiv C, Tudose M: Green synthetic strategies of oxide materials: polysaccharides-assisted synthesis. Rev Roum Chim 2010, 55:1017-1026.

24. Mazloumi M, Taghavi S, Arami H, Zanganeh S, Kajbafvala A, Shayegh MR, Sadrnezhaad SK: Self-assembly of ZnO nanoparticles and subsequent formation of hollow microspheres. J Alloys Compd 2009, 468(1-2):303-307.

25. Chittofrati A, Matijevic E: Uniform particles of zinc oxide of different morphologies. Colloids and Surfaces 1990, 48:65-78.

26. Ascough PL, Bird Ml, Francis SM, Lebl T: Alkali extraction of archaeological and geological charcoal: evidence for diagenetic degradation and formation of humic acids. J Archaeo/ Sci 2011, 38(1):69-78.

27. Zheng Y, Chen C, Zhan Y, Lin X, Zheng Q, Wei K, Zhu J, Zhu Y: Luminescence and photocatalytic activity of $\mathrm{ZnO}$ nanocrystals: correlation between structure and property. Inorg Chem 2007, 46(16):6675-82.

28. Meskinfam M: Synthesis and characterization of surface functionalized nanobiocomposite by nano hydroxyapatite. International Journal of chemical and Biological Engineering 2012, 6:192-195.

29. Ma X, Yu J, He K, Wang N: The effects of different plasticizers on the properties of thermoplastic starch as solid polymer electrolytes. Macromol Mater Eng 2007, 292(4):503-510.
30. Qian J, Wang J, Jin Z: Preparation of biomorphic SiC ceramic by carbothermal reduction of oak wood charcoal. Mater Sci Eng A 2004, 371(1-2):229-235.

31. Kizil R, Irudayaraj J, Seetharaman K: Characterization of irradiated starches by using FT-Raman and FTIR spectroscopy. J Agric Food Chem 2002, 50(14):3912-8.

32. Khamthong $P$, Lumdubwong $N$ : Effects of heat-moisture treatment on normal and waxy rice flours and production of thermoplastic flour materials. Carbohydr Polym 2012, 90:340-347.

33. Ciesielski W, Tomasik $P$ : Thermal properties of complexes of amaranthus starch with selected metal salts. Thermochim Acta 2003, 403(2):161-171.

34. Kruk M, Jaroniec M: Gas adsorption characterization of ordered organicinorganic nanocomposite materials. Chem Mater 2001, 13(10):3169-3183.

35. Yu J, Yu H, Cheng B, Zhao X, Zhang Q: Preparation and photocatalytic activity of mesoporous anatase $\mathrm{TiO} 2$ nanofibers by a hydrothermal method. Journal of Photochemistry and Photobiology A: Chemistry 2006, 182(2):121-127.

doi:10.1186/1752-153X-7-136

Cite this article as: Ramimoghadam et al:: Hydrothermal synthesis of zinc oxide nanoparticles using rice as soft biotemplate. Chemistry Central Journal 2013 7:136.

Publish with ChemistryCentral and every
scientist can read your work free of charge
"Open access provides opportunities to our
colleagues in other parts of the globe, by allowing
anyone to view the content free of charge."
W. Jeffery Hurst, The Hershey Company.
- available free of charge to the entire scientific community
- peer reviewed and published immediately upon acceptance
- cited in PubMed and archived on PubMed Central
- yours - you keep the copyright
submit your manuscript here:
http://www.chemistrycentral.com/manuscript/

